\title{
Cancer Patterns in Odisha - An Important Mining State in India
}

\author{
Sharmila Chatterjee, MBBS, MPH, $C P H^{1}$, Paul H Levine, $M D^{2,3}$, Surendra Nath Senapati, MD4, Dipti \\ Rani Samanta, $M D^{5}$ and Pinaki Panigrahi, $M D, P h D^{6^{*}}$
}

${ }^{1}$ Center for Global Health and Development, University of Nebraska Medical Center College of Public Health, Omaha, NE, USA

${ }^{2}$ Department of Epidemiology, University of Nebraska Medical Center College of Public Health, Omaha, NE, USA

${ }^{3}$ Asian Institute of Public Health Bhubaneswar, Odisha, India

${ }^{4}$ Department of Radiation Oncology, Acharya Harihar Regional Cancer Centre, Cuttack, Odisha, India

${ }^{5}$ Department of Medical Oncology, Acharya Harihar Regional Cancer Centre, Cuttack, Odisha, India

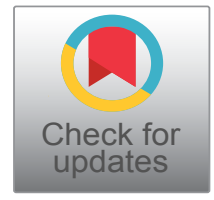

${ }^{6}$ Center for Global Health and Development, University of Nebraska Medical Center, College of Public Health, Omaha, NE, USA

*Corresponding author: Pinaki Panigrahi, MD, PhD, Center for Global Health and Development, College of Public Health, 984385 Nebraska Medical Center Omaha, NE 68198-4385, USA, Tel: +1402-552-6682

\begin{abstract}
Background: Odisha, a populous state and a major mining belt in India has high levels of environmental carcinogens. There is no population-based cancer registry in Odisha, thus giving no opportunity to develop systematic studies on important regional carcinogens. This paper highlights current patterns of cancer as seen at Acharya Harihar Regional Cancer Centre (AHRCC), and provides the first opportunity to determine the most important research questions that could drive cancer control programs in Odisha.

Methods: The analysis included all patients diagnosed and admitted with cancer at AHRCC, Cuttack, Odisha between January, $1^{\text {st }}$ and December, $31^{\text {st }}, 2012$. Patient data were extracted from inpatient records, investigation reports and from in-patient registers and admission registers maintained by the Medical Records Department. Relevant information on diagnosis, primary site and demographic data were retrieved.

Results: There were a total of 4811 patients, with a mean age of $47.5 \pm 15.5$ years, $44 \%$ males. The most common cancers among males were oral $(14 \%)$, gastric $(13 \%)$ and lung $(10 \%)$ cancers. For females, among the most common cancers were breast $(26 \%)$, cervix $(21 \%)$, ovary $(11 \%)$ gastric $(5 \%)$ and gall bladder $(3.7 \%)$. Seven percent of our cancer patients were aged $\leq 20$ years. Acute lymphoblastic leukemia, Non-Hodgkin's lymphoma, Hodgkin's lymphoma and brain tumors were most common in this age group.
\end{abstract}

Conclusion: Findings from this study suggest that particular attention be given to high prevalence cancers as import ant areas of research for risk factors and cancer control in Odisha.

\section{Keywords}

Cancer registry, Environmental carcinogens, India, Risk factors, Prevalence

\begin{abstract}
Abbreviations
AHRCC: Acharya Harihara Regional Cancer Centre; AIPH: Asian Institute of Public Health; CDC: Centers for Disease Control \& Prevention; HBCR: Hospital based cancer registry; H. pylori: Helicobacter pylori; HPV: Human papilloma virus; IARC: International Agency for Research on Cancer; ICD 10: International Classification of Diseases and Related Health Problems 10; ICMR: Indian Council of Medical Research; NCRP: National Cancer Registry Program; PBCR: Population based cancer registry; VIA: Visual inspection with acetic acid
\end{abstract}

\section{Introduction}

Cancer is the second most common fatal disease in India accounting for about $7 \%$ of annual deaths [1]. The number of prevalent cancer cases in India over 5 years is estimated to be around 2.3 millions with about 1.2 million new cases and 785 thousand deaths [2]. The total cancer burden in India is projected to increase substantially from about 1.2 million new cases in 2018 to more than 1.9 million by 2040 [3]. Recognizing the

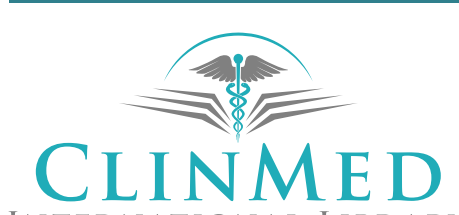

Citation: Chatterjee S, Levine PH, Senapati SN, Samanta DR, Panigrahi P (2019) Cancer Patterns in Odisha - An Important Mining State in India. Int J Cancer Clin Res 6:126. doi.org/10.23937/2378-3419/1410126 Accepted: October 12, 2019; Published: October 14, 2019

Copyright: (C) 2019 Chatterjee S, et al. This is an open-access article distributed under the terms of the Creative Commons Attribution License, which permits unrestricted use, distribution, and reproduction 
need for active cancer surveillance and cancer control activities in India, the Indian Council of Medical Research (ICMR) initiated the National Cancer Registry Programme (NCRP) with a network of cancer registries in 1981. The NCRP now comprises twenty seven Population-Based Cancer Registries (PBCRs) and seven Hospital-Based Cancer Registries (HBCRs). Published reports from these PBCRs and HBCRs have provided valuable information for setting priorities for cancer research and identified target sites - both anatomic and geographic - for cancer control measures [4].

Cancer patterns in India vary widely across regions and have been well documented in the registries under the NCRP [5]. Odisha, with a large population of $41,947,358$ has only recently been included under the NCRP with a Hospital-Based Registry (HBCR) (Figure 1) [6]. There is no existing published report on the status of cancer in the region. The state is in one of the largest mining belts in India, and its population is exposed to several mining products (asbestos, coal, cadmium, chromium, iron ore, nickel, quartz) [7]. Asbestos, cadmium, chromium and nickel have been designated as class 1 carcinogens to humans by the International Agency for Research on Cancer [8]. Higher concentrations of heavy metals (cadmium, chromium, and lead) have been reported among gall bladder cancer patients in India [9] and this is probably due to the presence of dangerously high concentrations of such metals in drinking water. Hence, it is extremely important to understand cancer patterns in Odisha, and focus on etiological factors for some of the most important cancers in the region, which will help formulate practical cancer control methods.

The Asian Institute of Public Health (AIPH) [10], situated in Odisha, has partnered with the Acharya Harihara Regional Cancer Centre (AHRCC) [11], a tertiary care center established to provide care of cancer cases in the state, thus allowing an opportunity to begin accumulating data on the most important cancers in the region. The data collected may thus foster further research efforts leading to improved cancer control in the state.

This paper provides a description of the data collected in the first year of this initiative and highlights obvious opportunities for cancer control in Odisha.

\section{Materials and Methods}

\section{Study setting}

The study was initiated at AHRCC, Cuttack in Odisha state, India. AHRCC established in 1983 has a total of

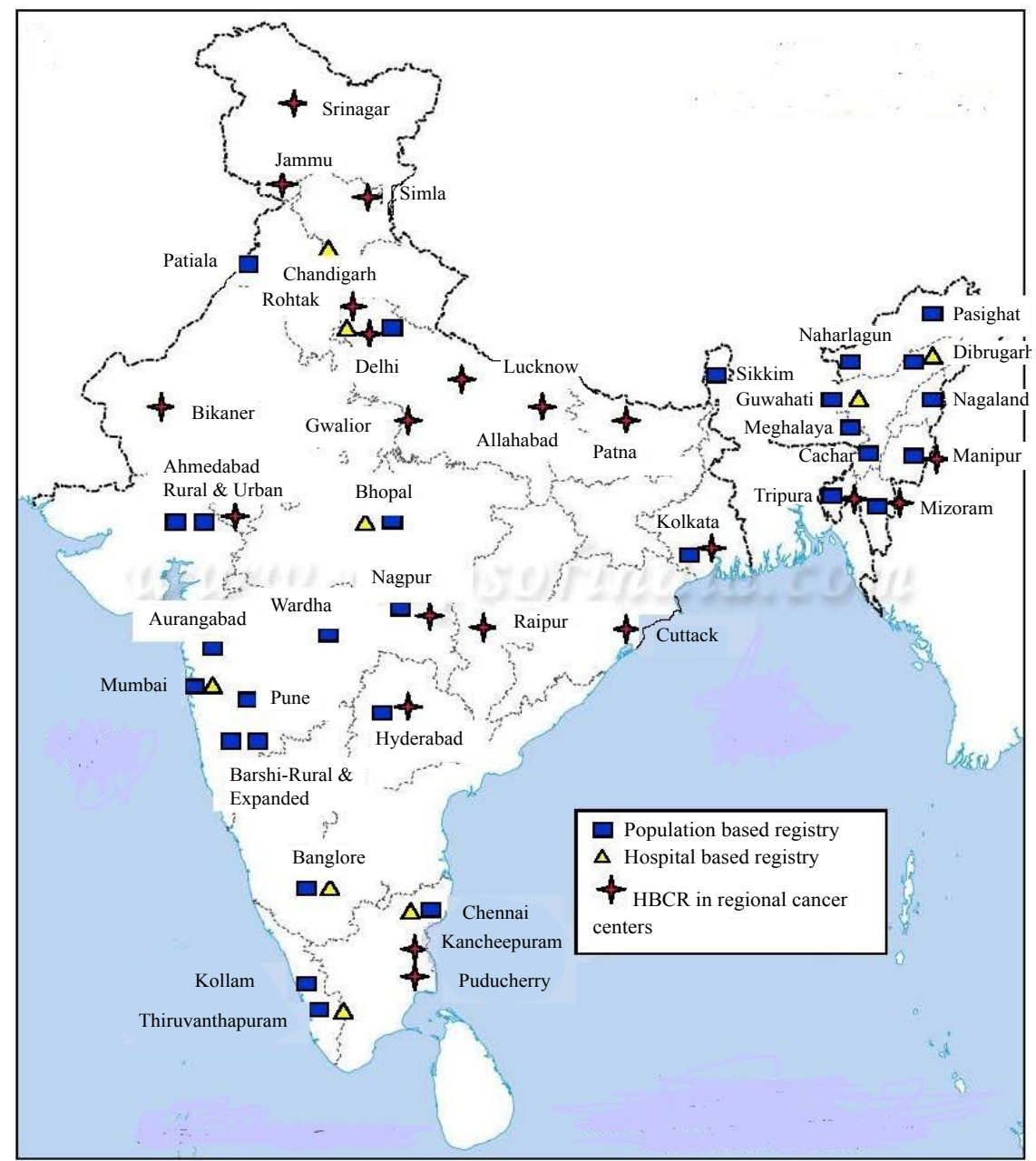

Figure 1: Showing the distribution of population based and hospital based cancer registries in India; HBCR at AHRCC Cuttack was set up in 2016. 
260 beds. Being the only regional cancer center in the state, AHRCC covers all 30 districts of Odisha state and also parts of neighboring states of West Bengal, Bihar, Jharkhand, Chhattisgarh and Andhra Pradesh. AHRCC is also the seat for the HBCR which was recently set up in Odisha.

\section{Study population and data source}

This analysis included all patients' histopathology proven cancer diagnosis and admitted at AHRCC between January $1^{\text {st }}$ and December, $31^{\text {st }}$ 2012. AHRCC 2012 data was used to enable us to compare with the latest published 2012-2014 NCRP consolidated reports. Data were abstracted from medical records according to a protocol which identified 26 items deemed important for epidemiological studies. In-patient registers and admission registers, maintained by the medical records department of AHRCC, were used to identify cancer patients admitted to the hospital during the period. Patient data were extracted from inpatient records and investigation reports.

Physicians-in-charge of patients were also interviewed to ensure consistency of data. For oral cancer, we included all cancers involving buccal mucosa, tongue, gum and palate.

\section{Data collection and variable information}

Two well trained data entry operators systematically reviewed medical records of identified cases and collected information on socio-demographic status, district of residence, diagnosis and primary tumor site and tumor characteristics (coded according to the $10^{\text {th }}$ Revision of the International Classification of Diseases and Related Health Problems (ICD10) with the codes C00-C97) (ICD 10, 2010) [12]. All data were entered in an electronic database created on an epi-info platform (Epi Info ${ }^{\mathrm{TM}}$ CDC, 2018) [13]. Any data discrepancy was cross-checked with patient records for errors during entry. All patient personal identifiers were removed from data files to maintain patient confidentiality. Quality of data was assessed by screening one hundred randomly selected records every month. Duplicate cases were eliminated by cross-checking the in-patient ID number of each patient.

\section{Statistical analysis}

The overall 2012 yearly prevalence of cancer and site specific cancers were determined for each district in Odisha and were categorized according to demographic characteristics (age, sex, religion, district of residence and income). 2011 Odisha Census population data [14] were used as the denominator population. Statistical reports in this study include absolute number of site-specific cancer cases, crude proportions, Odisha district specific prevalence rates, commonest cancers and the overall demographic profile. All statistical analysis was done using the PC-
SAS program (V9.2, SAS Institute, Cary, NC).

\section{Ethical approval}

This study was approved by the Ethical Review Boards of the AIPH and AHRCC.

\section{Results}

There were a total of 4811 patients ( 2108 males and 2703 females) admitted at AHRCC during the study period. The mean age of the population was $47.5 \pm 15.5$ years. At AHRCC, 6.8\% $(n=325)$ of the population constituted patients aged $\leq 20$ years.

Demographic characteristics of the studied population are described in Table 1.

Table 1: Shows the demographic characteristics of the studied population.

\begin{tabular}{|c|c|c|}
\hline Characteristics & $\mathbf{n}$ & $\%$ \\
\hline Total no. & \multicolumn{2}{|l|}{4811} \\
\hline \multicolumn{3}{|l|}{ Gender } \\
\hline Male & 2108 & 43.8 \\
\hline Female & 2703 & 56.2 \\
\hline \multicolumn{3}{|l|}{ Age group } \\
\hline$<=20$ & 325 & 6.8 \\
\hline $21-40$ & 1119 & 23.3 \\
\hline $41-60$ & 2519 & 53.4 \\
\hline $61-80$ & 819 & 17 \\
\hline$>80$ & 23 & 0.6 \\
\hline Missing data & 8 & 0.2 \\
\hline \multicolumn{3}{|l|}{ Religion } \\
\hline Hindu & 4708 & 97.7 \\
\hline Muslim & 101 & 2.1 \\
\hline Christian & 2 & 0.2 \\
\hline \multicolumn{3}{|l|}{ Occupation } \\
\hline \multicolumn{3}{|l|}{ Male } \\
\hline Farmer & 734 & 34.8 \\
\hline Business & 146 & 6.9 \\
\hline Student & 208 & 9.9 \\
\hline Daily wage laborer & 266 & 12.6 \\
\hline Service & 221 & 10.5 \\
\hline Others & 533 & 25.3 \\
\hline \multicolumn{3}{|l|}{ Female } \\
\hline House-wife & 2457 & 90.9 \\
\hline Service & 35 & 1.3 \\
\hline Others & 211 & 7.8 \\
\hline Missing data & 1639 & 34 \\
\hline Income & 3501 & 72.8 \\
\hline Low & 3502 & 72.7 \\
\hline Average & 1308 & 27.2 \\
\hline High & 1 & 0.01 \\
\hline Missing data & 1310 & 27.2 \\
\hline
\end{tabular}


Table 2: Shows the commonest cancer sites among males and females at AHRCC*.

\begin{tabular}{|c|c|c|c|c|c|}
\hline \multicolumn{3}{|l|}{ Male } & \multicolumn{3}{|l|}{ Female } \\
\hline Cancer site & $\mathrm{n}$ & $\%$ & Cancer site & $n$ & $\%$ \\
\hline Oral & 293 & 13.9 & Breast & 702 & 26 \\
\hline Gastric & 268 & 12.7 & Cervix & 560 & 20.7 \\
\hline Lung & 210 & 10 & Ovary & 289 & 10.7 \\
\hline NHL & 139 & 6.6 & Gastric & 138 & 5.1 \\
\hline Rectum & 133 & 6.3 & Uterus & 124 & 4.6 \\
\hline Gall bladder & 58 & 2.6 & Gall bladder & 100 & 3.7 \\
\hline
\end{tabular}

"AHRCC: Acharya Harihara Regional Cancer Centre.

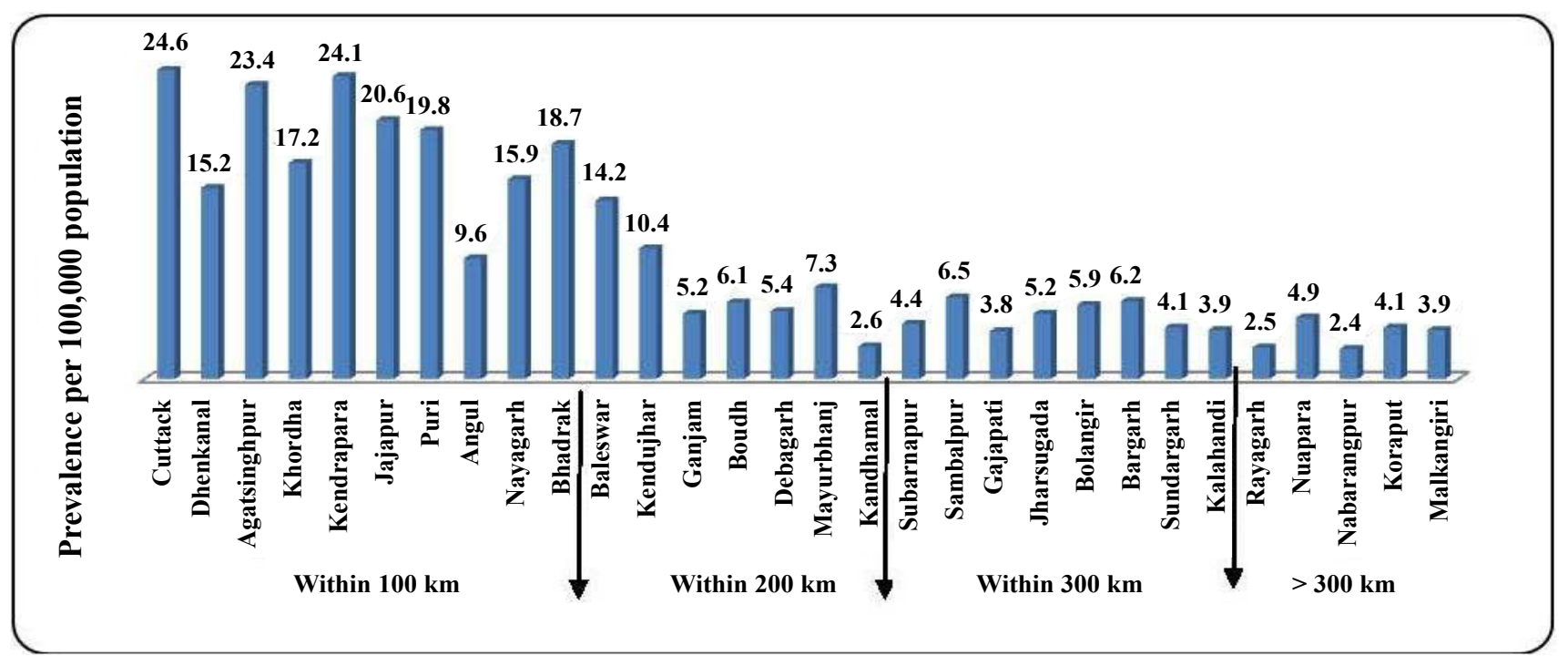

Figure 2: Showing all cancer prevalence per 100,000 population in Odisha districts- districts closest to AHRCC, Cuttack has a higher prevalence compared to districts away from AHRCC.

The most common cancers among males were oral (C01-C06 and C09), gastric (C16) and lung (C33-C34). Buccal mucosa (CO3-C04) and the tongue (C01-C02) were the most common oral cancers constituting $45 \%$ and $38 \%$ of all oral cancers respectively. For females, among the most common locations of primary cancers were breast (C50), cervix (C53), ovary (C56), gastric (C16) and gall bladder (C23-C24) (Table 2).

Hematological malignancies (acute lymphoblastic and myeloblastic leukaemia, chronic myelocytic and lymphocytic leukaemia (C91-C92), multiple myeloma (C90), Non-Hodgkin's lymphoma (C82-C85 and C96) and Hodgkin's lymphoma (C81) constituted $8.4 \%(n=402)$ of cases. Non Hodgkin's lymphoma was the commonest haematological malignancy. The commonest cancers in the $\leq 20$ year age group included acute lymphoblastic leukaemia $(n=60)$, Non-Hodgkin's lymphoma ( $n=$ $31)$, Hodgkin's lymphoma $(n=28)$ and brain tumours $(\mathrm{C} 70-\mathrm{C} 72)(\mathrm{n}=23)$.

Most cancer cases at AHRCC were reported from Cuttack $(n=644)$, Baleswar $(n=330)$, Bhadrak $(n=281)$, Dhenkanal $(n=181)$, Jagatsinghpur $(n=266)$, Jajapur ( $n$ $=377)$, Kendrapara $(n=347)$, Khordha $(n=387)$, Nayagarh $(n=153)$, Puri $(n=337)$, Kendujhar $(n=187)$ and
Angul $(n=122)$ districts. Figure 2 shows prevalence of all cancers in Odisha districts per 100,000 populations and the districts with higher proportion of cancer cases in proximity to AHRCC.

\section{Discussion}

This study represents the first attempt to systematically collect data from mixed rural, urban, and mining areas of Odisha with environmental factors notably different from those where the NCRP PBCRs and HBCRs are currently based. Oral cancers were the commonest cancer among males in Odisha, the most prevalent sites being buccal mucosa and tongue. This is a likely finding, with oral cancers being consistently reported as one of the commonest male cancers all over India [5]. The high prevalence of oral cancer in India has been attributed to use of tobacco smoking or chewing) $[15,16]$. Tobacco chewing in the form of betel quid referred to as pan and consisting of pieces of areca nut, processed or unprocessed tobacco, aqueous calcium hydroxide (slaked lime), and spices wrapped in the leaf of piper betel vine leaf, khaini and gutka is a common practice among males in Odisha. The general understanding about health threats associated with chewing and smoking is sparse among the younger population in Odisha, who 
do not hesitate to pick up the habit [17]. Thus the state government should strictly implement legislative measures for tobacco control in Odisha with utmost urgency and advocacy. It is also essential that the government implement urgent cost-effective oral cancer screening and awareness initiatives in such high-risk populations. A recent study from India has convincingly demonstrated that oral cancer screening by trained health workers can lower mortality of the disease - especially in individuals with a history of tobacco use [18]. Training individuals on self examination of mouth can also be a simple and cost-effective strategy to increase community awareness for oral cancer in Odisha.

Despite the overall nationally declining trend of cervical cancer, the proportion of cervical cancer cases among females in Odisha was much higher compared to other registries [5]. The high prevalence of cervical cancer cases is most likely due to insufficient screening and lack of state-wide government-sponsored public health policies on prevention of cervical cancer by screening procedures. The human papilloma virus (HPV) test, available in private sectors is very expensive. Cytology screening for cervical cancer introduced in the Indian public health services since the 1970s could not be well established due to lack of laboratory infrastructure including trained personnel, such as cyto-technicians and pathologists and continuous quality assurance process [19]. It is therefore, important that an alternative simpler, less expensive and promising screening method such as visual inspection of the cervix after application with acetic acid (VIA) [20] be considered for cervical cancer prevention programs in Odisha. The advantage of VIA is that it can be implemented through primary health-care workers and does not require a laboratory infrastructure. Moreover, the results are obtained immediately following testing, allowing diagnosis and treatment to be implemented during the same visit [21].

The high prevalence of cervical cancer in the state could also be attributed to lack of awareness about the disease and recent developments linking HPV to cervical cancer. A recent survey conducted in the year 2015 to assess community awareness of HPV screening and vaccination in Odisha showed that $22.4 \%$ of the surveyed population had heard of HPV and only $11.5 \%$ were aware that HPV caused cancer [22]. Community awareness and buy-in is critical for cervical cancer prevention [23] and it is important that aggressive public health campaigns be developed in the state to increase this awareness. Other public health measures such as health education, HPV vaccine, complimented with robust screening program at the state level will be essential to decrease cervical cancer prevalence in Odisha. Recent studies from Australia, one of the first countries to implement a fully government-funded, populationbased HPV vaccination program, have reported major decreases in vaccine-type HPV infection prevalence and associated disease incidence after implementation of HPV vaccine public health programs. The studies report reduction of HPV infections by $86 \%$ among 18 - to 24-year-olds who had received three vaccine doses and $76 \%$ for those who had received one or two doses $[24,25]$. Hence, an affordable, safe vaccination program can also be implemented to impact incidence and mortality of cervical cancer in Odisha.

One of the most striking finding in our population was identification of gastric cancer as the second most common cancer among men. There are several potential reasons for the high prevalence of gastric cancer in Odisha. Though Helicobacter pylori $(H$. pylori) infection has been considered as one of the most important etiological factors for gastric cancer [26], some epidemiological studies from India have failed to confirm the association [27]. The risk of $H$. pylori infection is directly related to overall sanitary conditions and contaminated water is often implicated as a possible mode of transmission in rural areas without reliable supplies of potable water [28]. A vast population attending AHRCC clinics come from rural areas and are therefore, likely to harbor $H$. pylori infection in their stomach. The infection by $H$. pylori may be prevented by interrupting transmission of the infection by promoting sanitary habits, good waste disposal, clean water supply and planned housing to minimize overcrowding [29].

Other factors demonstrated as significant dietary risk factors for gastric cancer in various parts of India include pickled food, high rice intake, spicy food, excess chilly consumption, consumption of high-temperature foods, smoked dried salted meat, use of soda and consumption of dried salted fish [30]. Improved food hygiene and dietary intervention with increased fruit and vegetable intakes and decreased consumption of salt or salt-preserved foods may act as primary prevention measures to reduce risk of gastric cancer in the state [31]. Healthy policies aimed at gastric cancer control such as disseminating information on diet changes, and improving awareness may also help reducing gastric cancer prevalence in Odisha.

Elevated gastric cancer incidence rates have also been demonstrated in the coal mining populations [31]. Dietary practices and rich resource of coal mines in Odisha may account for such high prevalence of gastric cancer in the region which needs to be further explored. Effective interventions should also be designed and implemented for population working in coal-mining industries such as assessing interim markers of exposure which could be used as proxies for gastric cancer.

Another important cancer requiring attention further research in Odisha is gall bladder cancer. Studies show that incidence of gallbladder cancer parallels prevalence of gall stone disease with large and long-standing gall 
stones being associated with a higher risk of gallbladder cancer [32]. Gall stone disease has also been implicated as one of the most important risk factors for gall bladder cancer in northern India [33]. However, the importance of gall stone disease as a causal factor for gall bladder cancer in Odisha needs further investigation.

Epidemiological studies show significant association between aflatoxin exposure and gall bladder cancer [34,35]. Aflatoxins, the toxic metabolites of Aspergillus flavus and Aspergillus parasiticus fungi, are naturally occurring contaminants of food and has been classified as a class 1 human carcinogen by the IARC [8]. Rice (Oryzae sativa L.) is the most important staple food crop in eastern India and bulk of rice is grown in kharif or wet season. Frequent and heavy rainfall and floods particularly near harvest in coastal areas of Odisha wet the crop and make panicles more prone to invasion by Aspergillus species and may likely attribute to rising proportion of gall bladder cancer cases in the state.

Environmental pollutants may also be implicated as important factor for gall bladder cancer in Odisha. Significant association of gall bladder cancer has been reported with the levels of heavy metals i.e. nickel, chromium and cadmium in the water $[33,36]$. Proximity to coal industries and mining exposures [8] may be factors that need to be explored as possible causes associated with gall bladder cancer in Odisha. Better designed case-control studies or cohort studies looking at various heavy metals are required to establish them as causal factors for gall bladder cancer in Odisha.

Other prevalent cancers noted in Odisha were lung and breast cancers. Apart from well established risk factors for lung cancer such as tobacco, diet and outdoor air pollutants [37], high prevalence of lung cancer in the region could be result of exposure to environmental contaminants associated with mining industries in the state $[38,39]$. Breast cancers more commonly occurred among younger women aged $\leq 45$ years. The rise in incidence of breast cancer at $0.5-2 \%$ per annum has been seen across all regions of India and in all age groups but more so in the younger age groups ( $<45$ years) $[40,41]$. The high prevalence of breast cancers in Odisha could be associated with socio-economic and life-style changes such as late childbearing, dietary changes and associated changes in menstrual patterns.

Our study also noted that overall prevalence of cancer varied geographically across districts of Odisha with higher prevalence of cancers in districts which were in closer proximity to AHRCC. This discrepancy in prevalence could due to easier access to AHRCC for patients from the more proximal districts. It may be speculated that cancer patients may have been treated in other hospitals in districts away from AHRCC and could not be captured in the AHRCC database. Probable exclusion of such cases may have resulted in under-counting of overall cancer cases thereby attenuating the true population estimates in districts away from AHRCC.
There are several limitations to our study. The database created was based on AHRCC in-patient records only. Hence, patients treated on an out-patient basis or those who underwent primary surgical treatment at private clinics and other surgical units may have been missed leading to under-estimation of some site-specific cancer cases. Moreover, the majority of patients admitted at AHRCC came from the neighboring districts. Odisha is a large state with several private and district hospitals offering cancer treatment. Hence, data only from AHRCC may not truly represent the status of cancer in Odisha state. However, in the absence of an established population-based cancer registry in Odisha, data from AHRCC can be regarded as the best possible estimates of cancer prevalence in Odisha.

Despite its limitation, this study has highlighted the need for increased attention to some of the important cancers in the state. These data are particularly useful in regard to selecting and implementing high impact cancer control programs. Aggressive screening and tobacco control should be implemented for cervical and oral cancers. Analytical studies should be focused on gastric and gall bladder cancers to determine etiology and other associated causes for the high prevalence of these cancers in the state and allowing targeted public health programs specific for the region.

\section{Acknowledgements}

We are grateful to Dr. Lalatendu Sarangi, Director AHRCC for his help in co-ordination and administrative support for the project and the data entry operators for digitization of the data.

\section{Statement Conflict of Interest}

The authors declare no conflict of interest.

\section{Authors' Contribution}

All authors have equally contributed to the conceptualization, planning, designing, conduct, analysis, reviewing, writing up and editing the final manuscript.

\section{References}

1. Jemal A, Siegel R, Ward E, Murray T, Xu J, et al. (2007) Cancer statistics, 2007. CA Cancer J Clin 57: 43-66.

2. Globocan India (2018).

3. Globocan 2018 Cancer Overtime.

4. (2019) National Cancer Registry Programme. About NCRP.

5. (2019) NCRP annual reports.

6. (2019) NCRP network.

7. (2019) Department of steel and mines, Government of Odisha.

8. (2018) IARC monographs on the identification of carcinogenic hazards to humans.

9. Shukla VK, Prakash A, Tripathi BD, Reddy DC, Singh S (1998) Biliary heavy metal concentrations in carcinoma of the gall bladder: case-control study. BMJ 317: 1288-1289. 
10. AIPH university.

11. Acharya Harihar Regional Cancer Center: Cancer Odisha.

12. International Statistical Classification of Diseases and Related Health Problems 10th Revision.

13. Epi-info. Centers for Disease Control and Prevention.

14. Orissa population census data 2011.

15. Jayalekshmi PA, Gangadharan P, Akiba S, Koriyama C, Nair RR (2011) Oral cavity cancer risk in relation to tobacco chewing and bidi smoking among men in Karunagappally, Kerala, India: Karunagappally cohort study. Cancer Sci 102: 460-467.

16. Coelho KR (2012) Challenges of the oral cancer burden in India. J Cancer Epidemiol 2012.

17. Panda B, Rout A, Pati S, Chauhan AS, Tripathy A, et al. (2012) Tobacco control law enforcement and compliance in Odisha, India--implications for tobacco control policy and practice. Asian Pac J Cancer Prev 13: 4631-4637.

18. Daftary DK (2010) Temporal role of tobacco in oral carcinogenesis:A hypothesis for the need to prioritize on precancer. Indian Journal of Cancer 1: 105-107.

19. Sankaranarayanan R, Budukh AM, Rajkumar R (2001) Effective screening programmes for cervical cancer in lowand middle-income developing countries. Bull World Health Organ 79: 954-962.

20. Sankaranarayanan R, Nene BM, Dinshaw K, Rajkumar R, Shastri S, et al. (2003) Early detection of cervical cancer with visual inspection methods: A summary of completed and on-going studies in India. Salud Pública de México 3: S399-S407.

21. Bobdey S, Sathwara J, Jain A, Balasubramaniam G (2016) Burden of cervical cancer and role of screening in India. Indian J Med Paediatr Oncol 37: 278-285.

22. Khanna N, Ramaseshan A, Arnold S, Panigrahi K, Macek MD, et al. (2015) Community awareness of HPV screening and vaccination in Odisha. Obstet Gynecol Int 2015.

23. (2018) IARC Cancer today.

24. Tabrizi SN, Brotherton JM, Kaldor JM, Skinner SR, Cummins E, et al. (2012) Fall in human papillomavirus prevalence following a national vaccination program. J Infect Dis 206: 1645-1651.

25. Garland SM, Kjaer SK, Muñoz N, Block SL, Brown DR, et al. (2016) Impact and effectiveness of the quadrivalent human papillomavirus vaccine: A systematic review of 10 years of real-world experience. Clin Infect Dis 63: 519-527.

26. Thirumurthi S, Graham DY (2012) Helicobacter pylori infection in India from a western perspective. Indian J Med Res 136: 549-562.
27. Phukan RK, Narain K, Zomawia E, Hazarika NC, Mahanta $\mathrm{J}$ (2006) Dietary habits and gastric cancer in Mizoram, India. J Gastroenterol 41: 418-424.

28. Ahmed KS, Khan AA, Ahmed I, Tiwari SK, Habeeb A, et al. (2007) Impact of household hygiene and water source on the prevalence and transmission of Helicobacter pylori: A South Indian perspective. Singapore Med J 48: 543-549.

29. Karimi P, Islami F, Anandasabapathy S, Freedman ND, Kamangar F (2014) Gastric Cancer: Descriptive Epidemiology, Risk Factors, Screening, and Prevention. Cancer Epidemiol Biomarkers Prev 23: 700-713.

30. Mathew A, Gangadharan P, Varghese C, Nair MK (2000) Diet and gastric cancer: A case- control study in South India. Eur J Cancer Prev 9: 89-97.

31. Bonequi P, Meneses-González F, Correa P, Rabkin CS, Camargo MC (2013) Risk factors for gastric cancer in Latin America: a meta-analysis. Cancer Causes Control 24: 217231.

32. O'Keeffe F, Lorigan G, Butler F (1989) Ultrasound findings in carcinoma of the gall bladder. Iri J Med Sci 158: 48-49.

33. Unisa S, Jagannath $P$, Dhir V, Khandelwal C, Sarangi L, et al. (2011) Population-based study to estimate prevalence and determine risk factors of gall bladder diseases in the rural Gangetic basin of North India. HPB (Oxford) 13: 117125.

34. Nogueira L, Foerster C, Groopman J, Egner P, Koshiol J, et al. (2015) Association of aflatoxin with gallbladder cancer in Chile. JAMA 313: 2075-2077.

35. Koshiol J, Gao YT, Dean M, Egner P, Nepal C, et al. (2017) Association of aflatoxin and gallbladder cancer. Gastroenterology 153: 488-494.

36. Pandey M (2006) Environmental pollutants in gallbladder carcinogenesis. J Surg Oncol 93: 640-643.

37. Lam WK, White NW, Chan-Yeung MM (2004) Lung cancer epidemiology and risk factors in Asia and Africa. Int J Tuberc Lung Dis 8: 1045-1057.

38. Jenkins WD, Christian WJ, Mueller G, Robbins KT (2013) Population cancer risks associated with coal mining: A systematic review. PLoS One 8: e71312.

39. Hendryx M, O’Donnell K, Horn K (2008) Lung cancer mortality is elevated in coal- mining areas of Appalachia. Lung Cancer 62: 1-7.

40. Murthy NS, Agarwal UK, Chaudhry K, Saxena S (2007) A study on time trends in incidence of breast cancer-Indian scenario. Eur J Cancer Care (Engl) 16: 185-186.

41. Agarwal G, Pradeep PV, Aggarwal V, Yip CH, Cheung PS (2007) Spectrum of breast cancer in Asian women. World J Surg 31: 1031-1040. 